Wright State University

CORE Scholar

2012

\title{
Atmospheric polycyclic aromatic hydrocarbon profiles and sources in pine needles and particulate matter in Dayton, Ohio, USA
}

Timothy A. Tomashuk

Triet Minh Truong

Wright State University - Main Campus

Madhavi Mantha

Audrey E. McGowin Ph.D.

Wright State University, audrey.mcgowin@wright.edu

Follow this and additional works at: https://corescholar.libraries.wright.edu/chem_student

Part of the Chemistry Commons

\section{Repository Citation}

Tomashuk, T. A., Truong, T. M., Mantha, M., \& McGowin, A. E. (2012). Atmospheric polycyclic aromatic hydrocarbon profiles and sources in pine needles and particulate matter in Dayton, Ohio, USA. . https://corescholar.libraries.wright.edu/chem_student/8

This Presentation is brought to you for free and open access by the Chemistry at CORE Scholar. It has been accepted for inclusion in Chemistry Student Publications by an authorized administrator of CORE Scholar. For more information, please contact library-corescholar@wright.edu. 


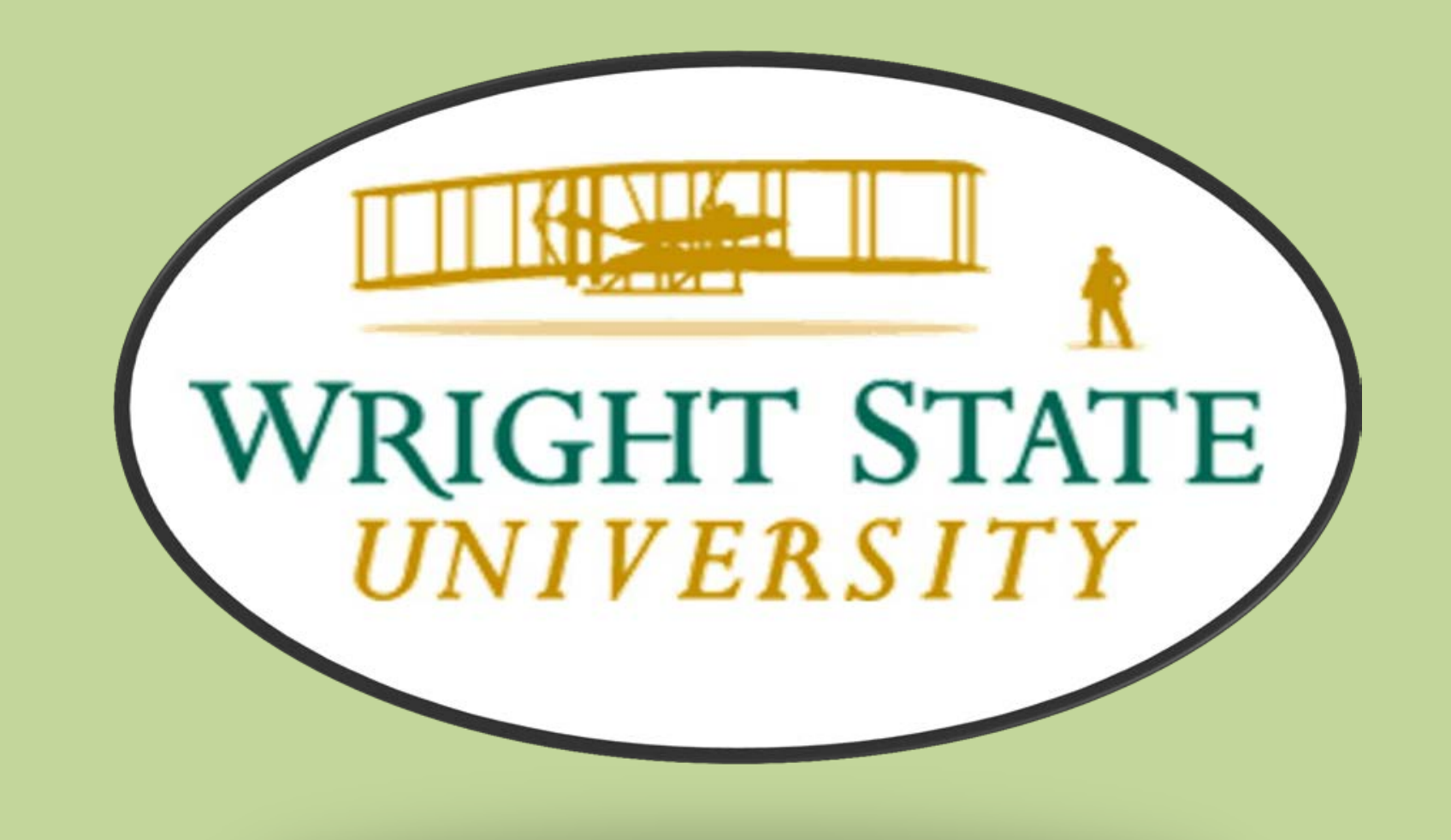

Atmospheric polycyclic aromatic hydrocarbon profiles and sources in pine needles and particulate matter in Dayton, Ohio, USA Timothy A. Tomashuk, Triet M. Truong, Madhavi Mantha, and Audrey E. McGowin, Ph.D. Department of Chemistry

स्ss
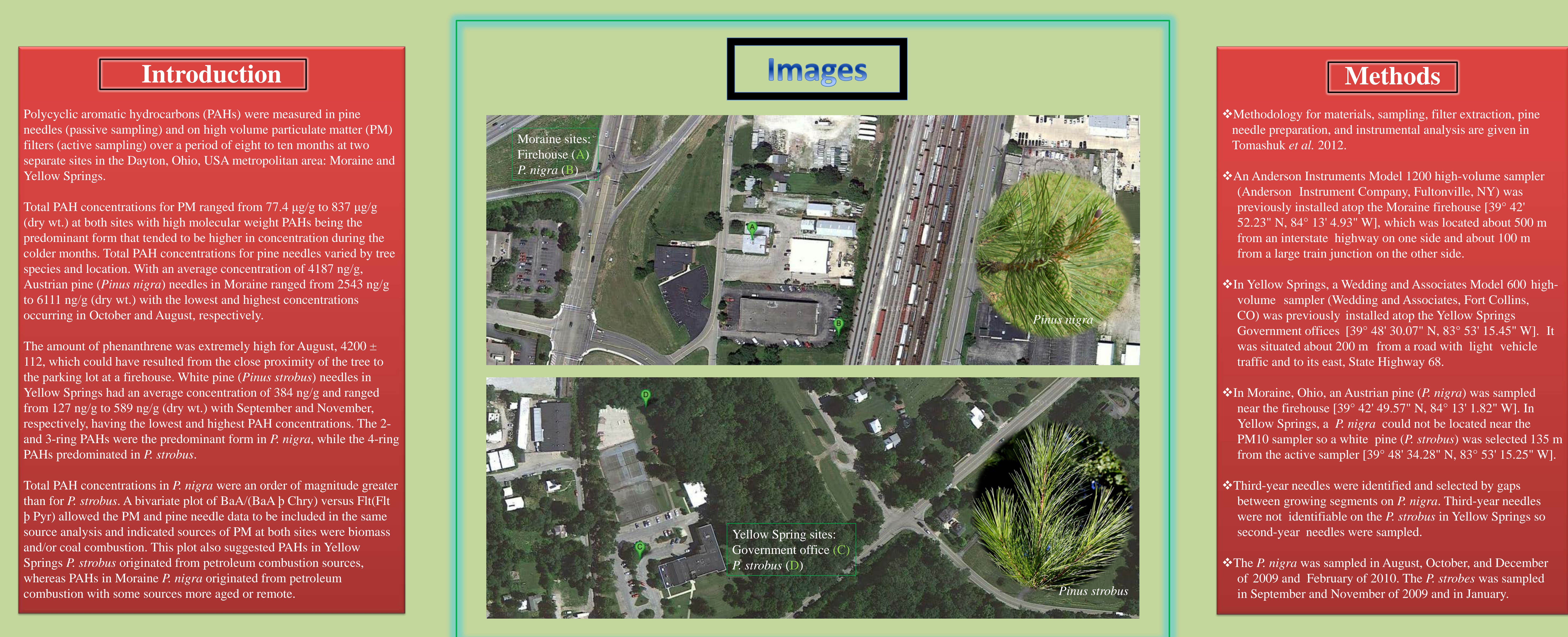

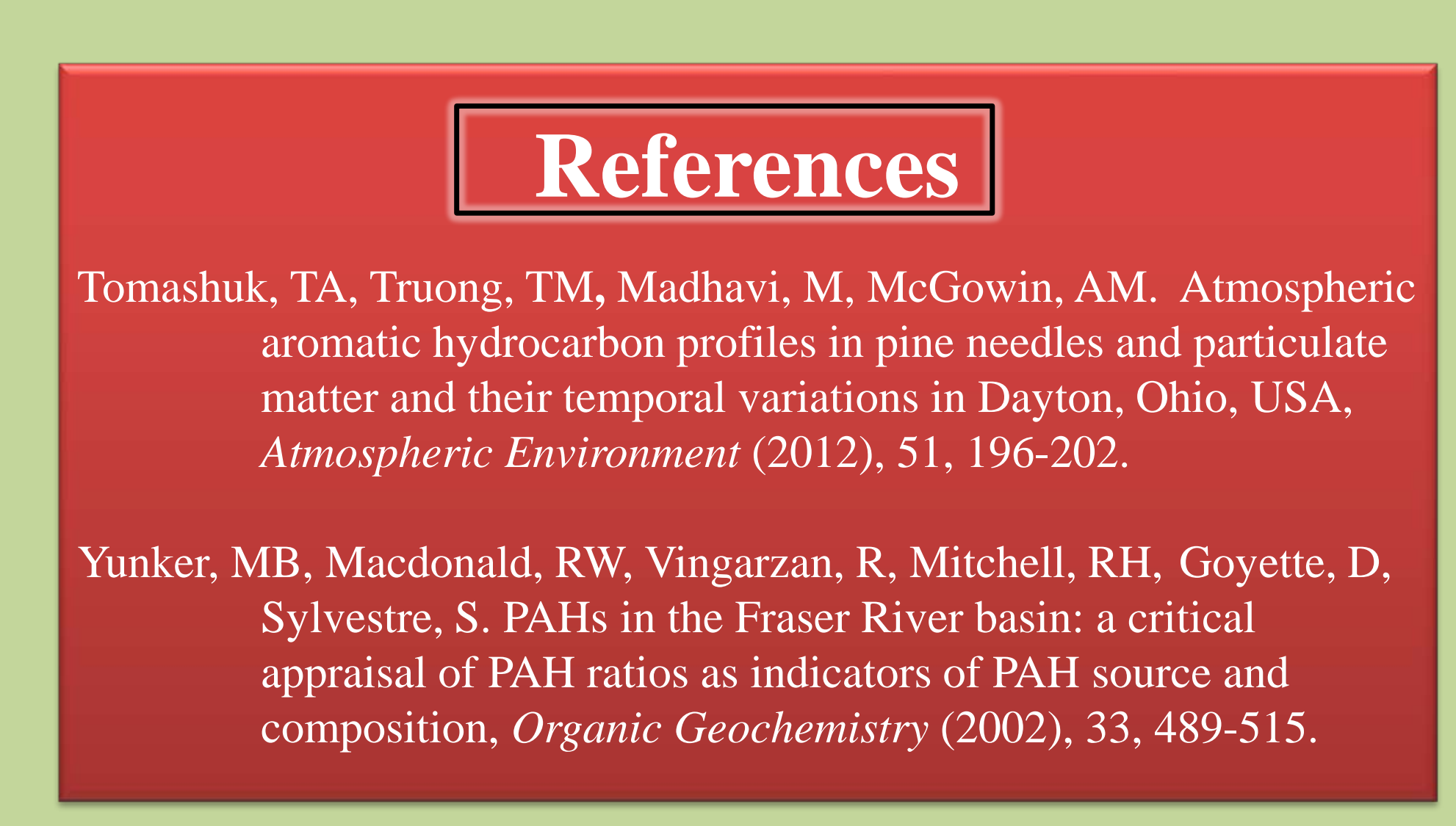

Acknowledgements

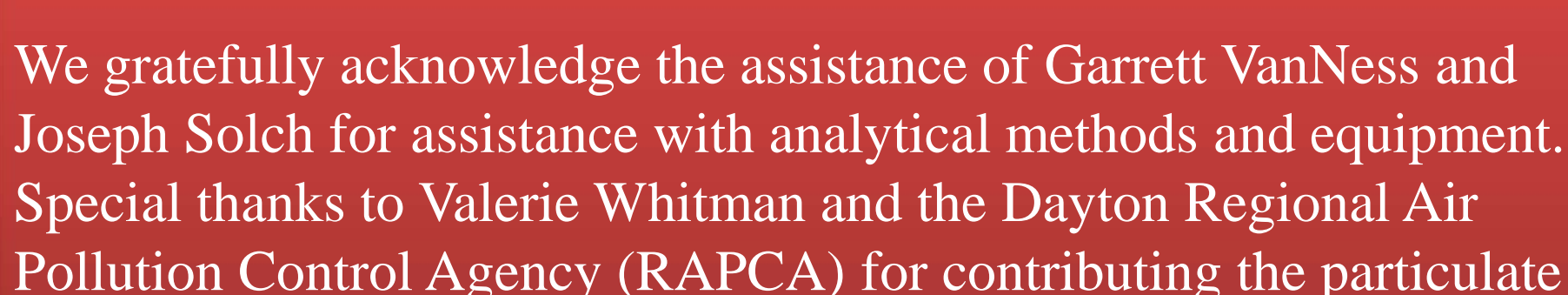

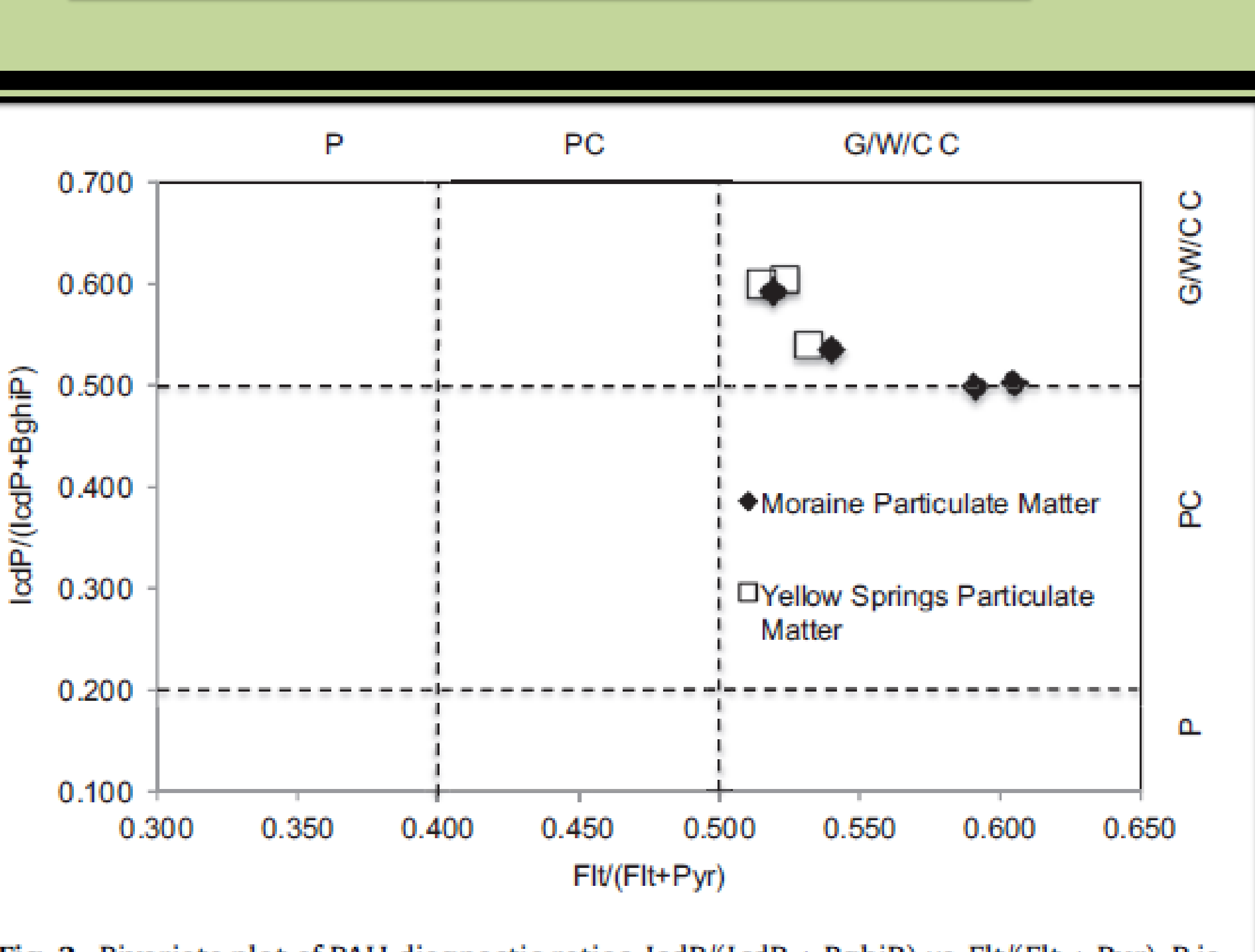

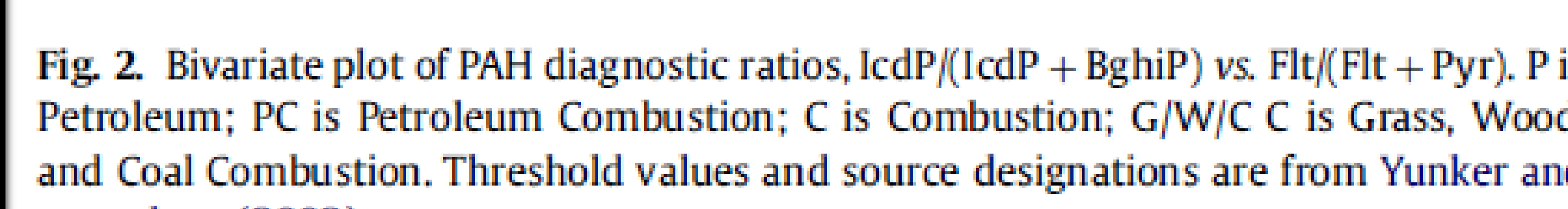


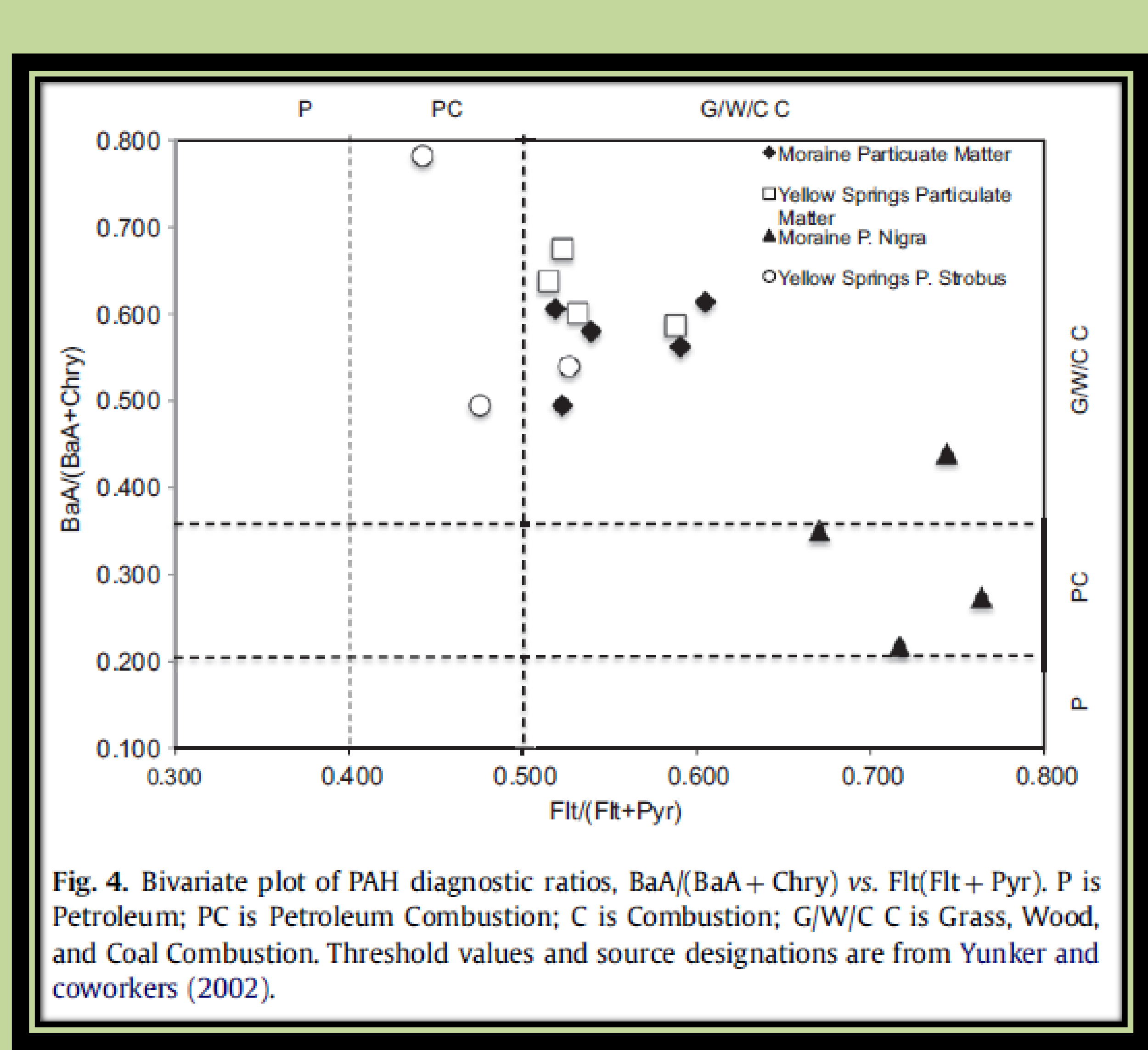

Results and Conclusions


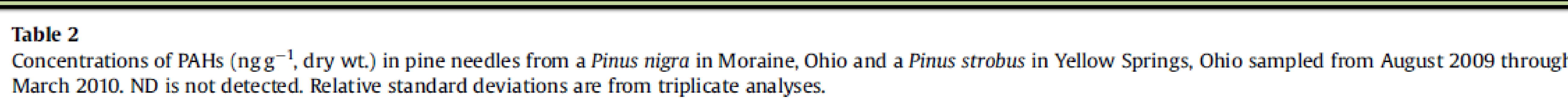
PAl

Naphthalene (Naph
Acenaphthene (Ace)



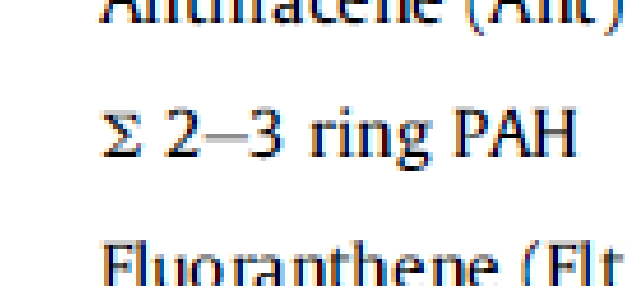

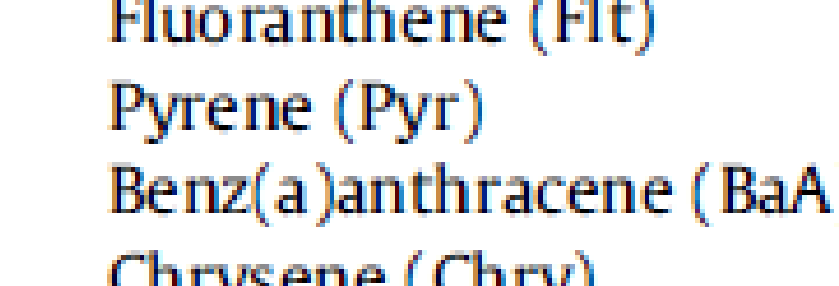

$\Sigma 4$ ring PAH

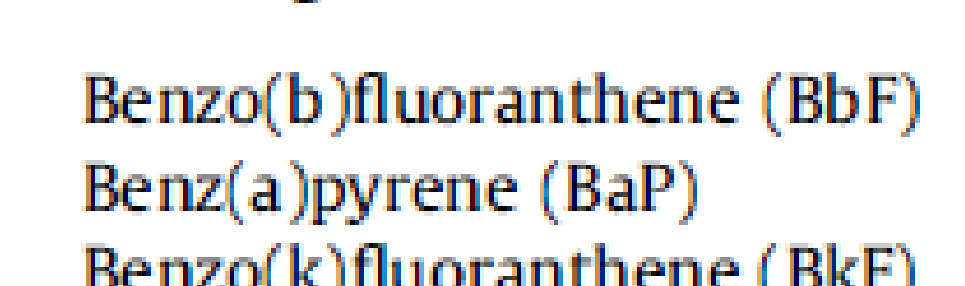

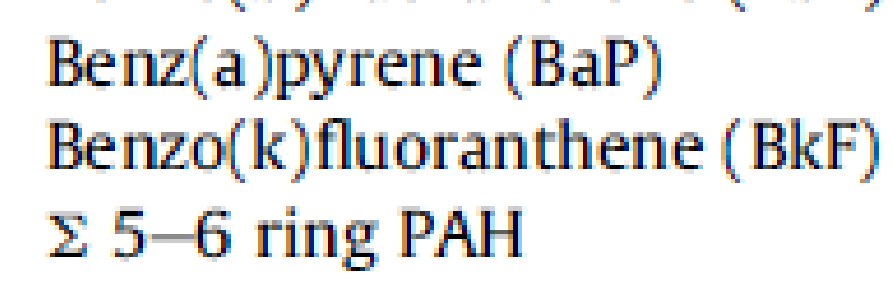

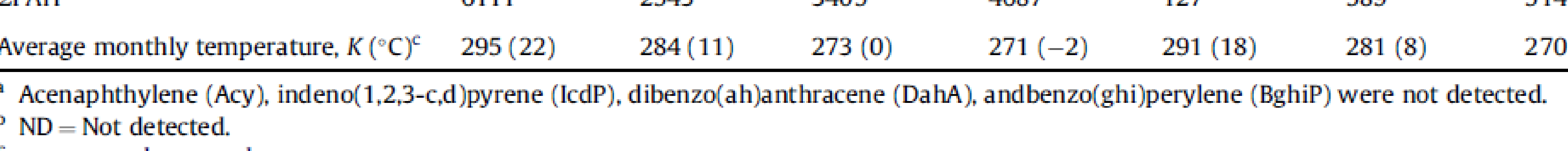

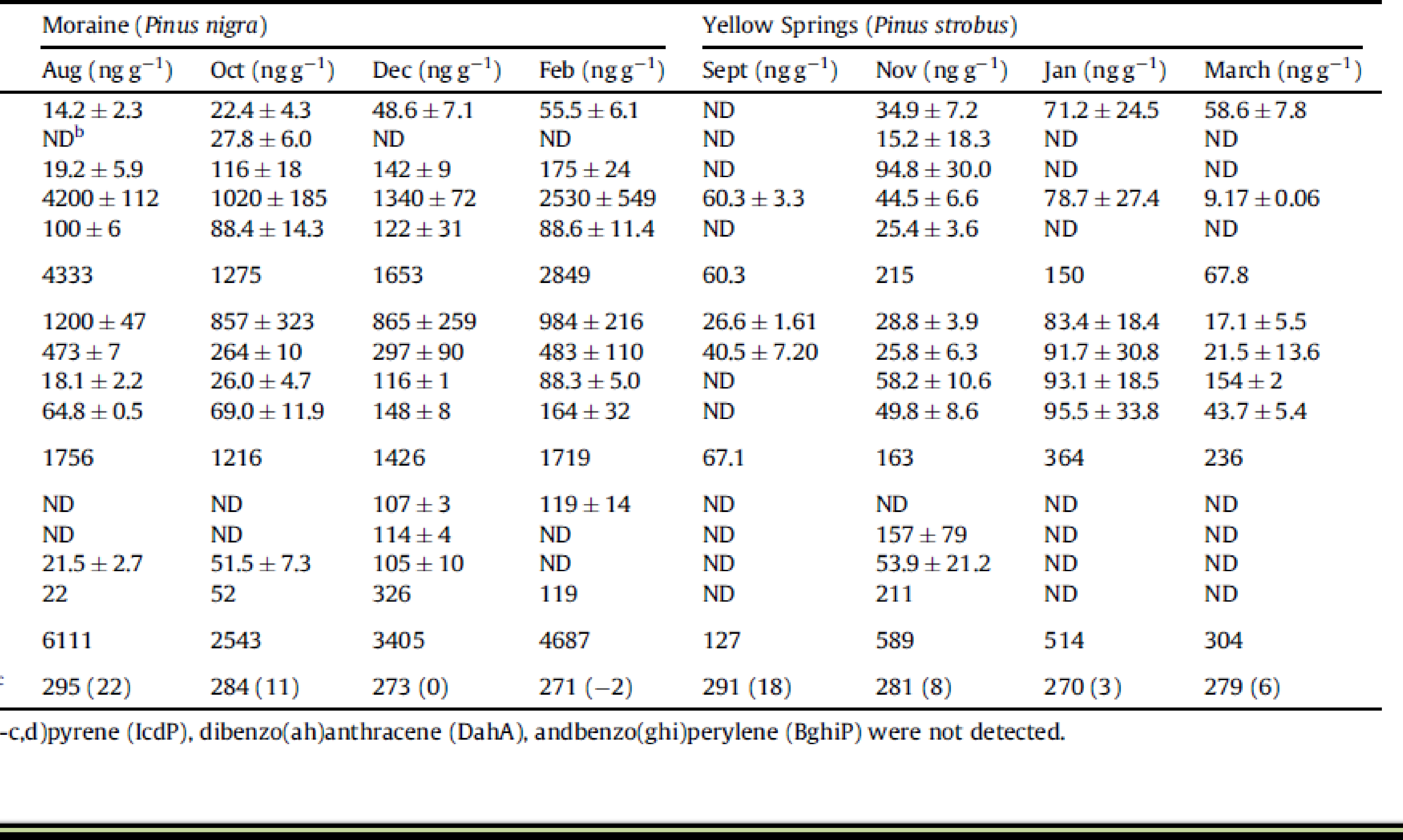

